\title{
ANALISIS TINGKAT KEUNTUNGAN USAHA PENGGEMUKAN SAPI POTONG RAKYAT DI KABUPATEN WONOGIRI
}

\author{
Analysis of Operating Profit Small Fattening Beef Cattle in Wonogiri District
}

\author{
Deasy Happyana
}

Department of Agribusiness, Faculty of Agriculture, Universitas Sebelas Maret Surakarta J1. Ir. Sutami No.36A, Jebres, Surakarta, Central Java 57126, Indonesia

email : deasyhappyana@yahoo.com

\begin{abstract}
Beef cattle breeding business in Wonogiri District is dominated by small scale in which capital and profits too low. The size of the profits derived from the balance of the sale value of production and production costs that is issued by the breeder. The maximum profit would be achieved if all factors of production have been allocated in an optimal and efficient use, both technically and economically efficient manner. Objective analysis profit function is to describe the situation now, the circumstances in the future or planning and action of a business related to the rate of business profit and net income scale beef cattle farms of the people. The results showed that total revenue (TR) of beef cattle breeding business people have an average of Rp.89.360.625.00 per farmer per one period of fattening cattle, while the total cost (TC) on average Rp.85.119.873.00 each farmers per one period of fattening cattle. So that the magnitude of the rate of profit $(\pi)$ obtained by each farmer in one period of fattening cattle for Rp.4.240.752.00 and the $R / C$ ratio of 1:05. The results of the analysis showed that the profit rate of beef cattle breeding business in Wonogiri Regency financially advantageous (value profit $\pi>0$ and the return value cost ratio of $R / C>$ 1). Results of regression equation analysis function simultaneously benefit breeders show concentrate feed costs, labor costs and costs of cows significant $((P<0.05))$ on the level of business profit beef cattle farms in Wonogiri. Based on the calculation of the value of $R^{2}$ adjusted Rvalues obtained $23.2 \%$ showed variable variation concentrate feed and forage costs, drug costs, labor costs, fees and charges cage feeder cattle can be explained by either a variable rate of the business profits of beef cattle breeders. The remaining $16.8 \%$ operating income level variable cattle ranchers explained by variations in other variables outside the model. Partially variable concentrate feed costs, labor costs and the cost of feeder cattle significantly $(P<0.05)$ to the level of business profit breeding beef cattle people. As for the cost of forage ariable drug costs are not significant $(P>0.5)$ on the level of beef cattle breeding business benefit of the people.
\end{abstract}

Keywords: Function Gain, Beef Cattle, Wonogiri

\section{PENDAHULUAN}

Strategi pembangunan peternakan mempunyai prospek yang baik dimasa depan, karena permintaan akan bahan-bahan yang berasal dari ternak akan terus meningkat seiring dengan peningkatan jumlah penduduk, pendapatan, dan kesadaran masyarakat untuk mengkonsumsi pangan bergizi tinggi sebagai pengaruh dari naiknya tingkat pendidikan ratarata penduduk (Santosa, 1996).

Pembangunan dan pengembangan tersebut salah satunya adalah pembangunan di bidang pertanian yang meliputi pembangunan di bidang peternakan, dimana salah satu usaha peternakan yang banyak di lakukan oleh masyarakat di pedesaan adalah beternak sapi potong, yang berbentuk usaha peternakan rakyat.
Berkaitan dengan hal tersebut, perlu di identifikasi alternatif pola pengembangan peternakan rakyat yang mernpunyai skala usaha yang ekonomis yang mampu memberikan kontribusi terhadap pendapatan keluarga yang cukup memadai. Kecilnya skala usaha peternakan sapi potong di Kab. Wonogiri yang dominan di sebabkan oleh masalah skala kepemilikan modal peternak yang terbatas sehingga berakibat pada rendahnya pendapatan yang di terima. Tingkat pendapatan berkaitan dengan tingkat keuntungan yang optimal sehingga peternak harus memahami aspek aspek teknis dan ekonomis produksi. Besar kecilnya keuntungan yang diperoleh akan sangat di tentukan oleh nilai jual hasil produksi dan biaya produksi yang di keluarkan oleh peternak. Keuntungan maksimum akan dicapai apabila semua faktor produksi telah dialokasikan 
penggunaannya secara optimal dan efisien, baik efisien secara teknis dan ekonomis. Artinya peternak harus optimal dalam menggunakan input produksi agar tercapai suatu produktivitas yang tinggi sekaligus melakukan efisiensi biaya. (Mandaka dan Hutagaol, 2005)

Tujuan analisis fungsi keuntungan ini adalah juga untuk menggambarkan keadaan sekarang, keadaan yang akan datang atau perencanaan dan tindakan dari suatu usaha . Sehingga untuk mengetahui tingkat keuntungan usaha, skala hasil usaha peternakan sapi potong rakyat, maka perlu dilakukan suatu penelitian tentang analisis fungsi keuntungan peternakan sapi potong di Kab. Wonogiri.

\section{MATERI DAN METODE}

Penelitian ini dilaksanakan pada usaha penggemukan sapi potong Kelompok Tani Ternak Sapi Potong di Kabupaten Wonogiri, dalam periode waktu pemeliharaan Tahun 2015.

\section{Populasi dan Teknik Pengambilan Sampel}

Populasi adalah kelompok elemen yang lengkap yang biasanya berupa orang, objek, transaksi, atau kejadian di mana kita tertarik untuk mempelajarinya atau menjadi obyek penelitian (Supranto, 2000). Dalam penelitian ini, populasi yang diambil adalah Kelompok Tani Ternak Sapi Potong di Kabupaten Wonogiri. Dalam penelitian ditetapkan 6 (Enam) kecamatan secara sengaja (purposive sampling) dimana keenam kecamatan ini yang menurut data dari Dinas Peternakan dan Perikanan Kabupaten Wonogiri merupakan kecamatan yang melakukan usaha penggemukan ternak sapi potong dalam periode penggemukan 4 bulan (Dinas Peternakan dan Perikanan Kabupaten Wonogiri, 2015).

Penelitian ini mengambil sampel sebanyak 100 peternak, dengan didasarkan pada asumsi dalam pengelolaan usaha peternakan sapi potong terdapat homogenitas dari populasi, atau dengan mempertimbangkan tingkat homogenitas peternak yang relatif tinggi dalam hal cara beternak sapi potong, faktor produksi yang digunakan dan penanganan produksi. Hal ini juga sesuai dengan Singarimbun dan Efendi (1989) dan Singarimbun (1997) bahwa bila suatu data dianalisis dengan statistik parametrik, maka jumlah sampel harus besar, karena nilai-nilai atau skor yang diperoleh distribusi harus mengikuti distribusi normal, sampel yang tergolong sampel besar yang distribusinya normal adalah sampel yang jumlahnya $>30$ diambil secara acak (random).
Adapun pengambilan sampel yang dilakukan dengan metode proportional sampling dengan rumus sebagai berikut:

$$
\mathrm{NK}=\frac{\mathrm{P}_{\mathrm{K}}}{\mathrm{P}} x \mathrm{~N}
$$

Keterangan:

NK : jumlah sampel yang diambil pada kecamatan $\mathrm{k}$

$\mathrm{P}_{\mathrm{K}} \quad$ : populasi pada kecamatan

$\mathrm{P} \quad$ : populasi seluruhnya

$\mathrm{N} \quad$ : total sampel

Tabel 1. Perhitungan Jumlah Sampel Penelitian

\begin{tabular}{lccc}
\hline Kecamatan & $\begin{array}{c}\text { Jumlah } \\
\text { Peternak }\end{array}$ & Pk/P & $\begin{array}{c}\text { Jumlah } \\
\text { Sample }\end{array}$ \\
\hline Ngadirojo & 4.791 & 0,2408 & 24 \\
Baturetno & 4.076 & 0.2049 & 20 \\
Wuryantoro & 3.538 & 0.1778 & 18 \\
Jatipurno & 2.755 & 0.1395 & 15 \\
Nguntoronadi & 2.463 & 0.1238 & 12 \\
Wonogiri & 2.266 & 0.1139 & 11 \\
\hline Total & 19889 & 10000 & 100 \\
\hline
\end{tabular}

Sumber : Disnakperla Kab. Wonogiri 2015

Pengambilan sampel dilakukan secara purposive sampling, yaitu pemilihan sampel secara sengaja yang didasarkan pada tujuan tertentu yaitu jumlah kepemilikan ternak sapi potong. Pemilihan sampel yang dilakukan secara sengaja dimaksudkan untuk mendapatkan tujuan dari penelitian.Pada umumnya ukuran sampel yang digunakan adalah antara 30 sampai 500 elemen menurut Roscoe (1975) dalam Sekaran (1992) maka penulis mengambil sampel sebanyak 100 peternak.

\section{Jenis dan Sumber Data}

Data primer, yaitu data yang berisikan data mengenai biaya input yang dikeluarkan dan penerimaan dari usaha penggemukan dalam satu masa penggemukan yang diperoleh dari sampel peternak sapi potong. Data primer ini diperoleh dari survai lapang (field survey) dengan melakukan wawancara mendalam (indepth interview) dan pengisian kuesioner terstruktur dengan peternak sampel. Data primer yang digunakan merupakan data cross section, maksudnya adalah pengambilan data dilakukan pada tahun yang sama. Data ini adalah data-data yang akan meliputi variabel dalam penelitian serta informasi tentang gambaran dari usaha yang dilakukan oleh peternak sapi potong.

Data sekunder, yaitu berisikan data pendukung penelitian mengenai usaha peternakan sapi potong yang diperoleh dengan mengumpulkan data yang telah ada pada instansi-instansi terkait dan publikasi dari lembaga-lembaga yang relevan dengan 
penelitian ini. Data sekunder yang digunakan dalam penelitian ini berupa data peternak, profil peternakan, gambaran umum daerah penelitian, populasi, produksi petemakan, dan potensi pengembangan peternakan dan data-data pendukung lain yang didapat dari instansiinstansi yang berkaitan di kabupaten dan daerah sampel.

\section{Variabel Penelitian dan Analisis Data}

Variabel dalam penelitian ini meliputi :

$=$ Tingkat keuntungan (selisih antara hasil penjualan dengan total biaya) .

$\mathrm{W}_{1}{ }^{*} \quad=$ Biaya konsentrat

$\mathrm{W}_{2}{ }^{*} \quad=$ Biaya hijauan

$\mathrm{W}_{3}{ }^{*} \quad=$ Biaya obat .

$\mathrm{W}_{4}{ }^{*} \quad=$ Biaya tenaga kerja .

$\mathrm{W}_{5}{ }^{*} \quad=$ Biaya sapi bakalan .

$\mathrm{W}_{6}{ }^{*} \quad=$ Biaya Penyusutan Kandang .

Teknik analisis data sebagai berikut:

Analisis terhadap hipotesis pertama untuk mengetahui deskripsi tingkat keuntungan (profit description) dari usaha peternakan sapi potong. Kondisi ini dapat diketahui dengan mendeskripsikan seberapa besar tingkat penerimaan total dan biaya-biaya yang dikeluarkan. Tujuan utama suatu usaha secara umum adalah memperoleh laba maksimal. Laba adalah total penerimaan $(\mathrm{TR}=$ Total Revenue $)$ dikurangi dengan total biaya $(\mathrm{TC}=$ Total Cost $)$. Jadi laba ditentukan oleh dua hal yakni penerimaan dan biaya. Jadi perubahan laba yang akan didapatkan tergantung dari perubahan penerimaan $(\mathrm{MR}=$ Marginal Revenue $)$ dan perubahan biaya $(\mathrm{MC}=$ Marginal Cost $)$.

Menurut Soekartawi (2003) bahwa kondisi usaha dapat diketahui dengan mendeskripsikan seberapa besar tingkat penerimaan total dan biayabiaya yang dikeluarkan dengan rumus sebagai berikut:

$$
\begin{aligned}
& \mathrm{K}=\operatorname{Pr} . \mathrm{T}-\mathrm{B} \\
& \mathrm{K}=\operatorname{Pr} \mathrm{T}-(\mathrm{BT}+\mathrm{BTT})
\end{aligned}
$$

Keterangan:

$$
\begin{array}{ll}
\mathrm{K} & =\text { Keuntungan } \\
\text { Pr.T } & =\text { Penerimaan total } \\
\mathrm{BT} & =\text { Biaya tetap } \\
\text { BTT } & =\text { Biaya tidak tetap }
\end{array}
$$

Dikarenakan biaya produksi adalah banyaknya input dikalikan harganya, maka tingkat keuntungan dari usaha peternakan tersebut dapat dihitung sebagai berikut:

$$
\begin{gathered}
\mathrm{K}=\mathrm{Py} \cdot \mathrm{Y}-\left(\mathrm{P}_{\mathrm{x} 1} \cdot \mathrm{X}_{1}+\mathrm{P}_{\mathrm{X} 2} \cdot \mathrm{X}_{2}+\mathrm{P}_{\mathrm{X} 3} \cdot \mathrm{X}_{3}+\mathrm{P}_{\mathrm{X} 4} \cdot \mathrm{X}_{4}\right. \\
\left.+\mathrm{P}_{\mathrm{x} 5} \cdot \mathrm{X}_{5}+\mathrm{P}_{\mathrm{x} 6} \cdot \mathrm{X}_{6}\right)
\end{gathered}
$$

Keterangan :

Py = Harga jual sapi potong (Rp)

$\mathrm{Y} \quad=$ Produksi sapi potong (Ekor)

$\mathrm{P}_{\mathrm{X} 1} \quad=$ Harga pakan konsentrat $(\mathrm{Rp})$

$\mathrm{X}_{1} \quad=$ Jumlah pakan konsentrat $(\mathrm{Kg})$

$\mathrm{P}_{\mathrm{X} 2} \quad=$ Harga pakan hijauan $(\mathrm{Rp})$

$\mathrm{X}_{2} \quad=$ Jumlah pakan hijauan $(\mathrm{Kg})$

$\mathrm{P}_{\mathrm{X} 3} \quad$ = Harga obat-obatan $(\mathrm{Rp})$

$\mathrm{X}_{3} \quad$ = Jumlah obat-obatan (Set)

$\mathrm{P}_{\mathrm{X} 4} \quad=$ Harga upah tenaga kerja $(\mathrm{Rp})$

$\mathrm{X}_{4} \quad=$ Jumlah tenaga kerja $(\mathrm{JOK})$

$\mathrm{P}_{\mathrm{x} 5} \quad=$ Harga sapi bakalan $(\mathrm{Rp})$

$\mathrm{X}_{5} \quad=$ Jumlah sapi bakalan (Ekor)

$\mathrm{P}_{\mathrm{x} 6} \quad=$ Harga Kandang $(\mathrm{Rp})$

$\mathrm{X}_{6} \quad=$ Penyusutan Kandang (periode)

Jika $\mathrm{K}>0$, maka usaha peternakan sapi potong tersebut menguntungkan.

Jika $\mathrm{K}<0$, maka usaha peternakan sapi potong tersebut tidak menguntungkan.

Analisis kedua diuji dengan menggunakan fungsi keuntungan dengan teknik Unit Output Price (UOP) Cobb-Douglas Profit Function (UOP-CDPF) melalui analisis regresi berganda. Di Indonesia, fungsi keuntungan ini telah banyak digunakan untuk penelitian terhadap berbagai jenis usaha, termasuk usaha peternakan sapi potong rakyat. Spesifikasi fungsi keuntungan yang digunakan dalam penelitian ini adalah fungsi keuntungan Cobb-Douglas yang diturunkan dari fungsi produksi Cobb-Douglas.

Dengan alat analisis ini, maka hampir semua parameter yang berkaitan langsung dengan produksi dapat diperoleh (Simatupang, 1988). Alasan lain penggunaan model analisis fungsi keuntungan menurut Lau and Yotopoulus (1972) cit Andri (1992) adalah karena model ini dinilai memiliki beberapa kelebihan bila dibandingkan dengan fungsi produksi dan program linier, diantaranya adalah:

- Fungsi penawaran ouput dan fungsi permintaan input dapat diduga bersamasama tanpa harus membuat fungsi produksi yang eksplisit.

- Fungsi keuntungan dapat digunakan untuk menelaah efisiensi teknis, harga dan ekonomi.

Di dalam model fungsi keuntungan, peubah-peubah yang diamati adalah peubah harga output dan input.

Fungsi keuntungan Cobb-Douglas tersebut menggunakan model regresi linier berganda (multiple linier regression) yang sebelumnya telah dinormalkan dahulu dengan unit harga output (UOP) dan ditransformasikan dalam bentuk logaritma, sehingga persamaannya adalah sebagai berikut: 


$$
\begin{gathered}
\text { In }{ }^{*}={ }_{0}+{ }_{1} \operatorname{In~}_{1}{ }^{*}+{ }_{2} \operatorname{In~}_{2}{ }^{*}+{ }_{3} \text { In } W_{3}{ }^{*}+{ }_{4} \text { In } \\
W_{4}{ }^{*}+{ }_{5} \text { in } W_{5}{ }^{*}+e_{i}
\end{gathered}
$$

Keterangan :

$=$ Tingkat keuntungan (selisih antara hasil penjualan dengan biaya) yang telah dinormalkan dengan tingkat harga output.

$\mathrm{W}_{1}{ }^{*} \quad$ = Biaya konsentrat

$\mathrm{W}_{2}{ }^{*} \quad$ Biaya hijauan

$\mathrm{W}_{3}{ }^{*} \quad$ Biaya obat

$\mathrm{W}_{4}{ }^{*} \quad$ = Biaya tenaga kerja

$\mathrm{W}_{5}{ }^{*} \quad=$ Biaya sapi

$\mathrm{W}_{6}{ }^{*} \quad$ Biaya Penyusutan Kandang ..

$0=$ Konstanta / intersep

1-4 = Koefisien regresi variabel independen

$\mathrm{e}_{\mathrm{i}} \quad=$ Variabel gangguan

Setelah didapat koefisien regresi dari masing-masing variabel, selanjutnya dilakukan uji asumsi klasik untuk menguji apakah model penelitian ini bisa digunakan atau tidak sehingga akan menghasilkan koefisien regresi yang tidak bisa, dan uji statistik untuk menentukan tingkat signifikansinya. Uji yang digunakan adalah:

a. Uji Asumsi Klasik

Dalam penelitian ini untuk mencari koefisien regresi digunakan metode kuadrat terkecil (OLS = Ordinary Least Square) yang bertujuan untuk melihat apakah regresi bermasalah atau tidak sehingga akan menghasilkan koefisien regresi yang tidak bias. Agar diperoleh koefisien regresi yang linier terbaik tidak bias harus dipenuhi beberapa asumsi klasik (Gujarati, 1999). Asumsi klasik ini diantaranya bahwa semua kesalahan penganggu variasinya sama (homoskedastisitas), tidak ada gejala auto korelasi antara kesalahan penganggu dan tidak ada kolinieritas ganda (multikolinieritas) antara variabel bebas (Soeharno, 2006).

Pelanggaran terhadap asumsi-asumsi klasik tersebut dapat diketahui melalui pengujian terhadap gejala multikolinieritas dan heteroskedastisitas.

\section{b. Uji Multikolinieritas}

Multikolinieritas merupakan suatu

keadaan dimana dalam satu atau lebih variabel independen terdapat korelasir atau hubungan dengan variabel independen lainnya. Dengan kata lain satu atau lebih variabel independennya merupakan suatu fungsi linier dari variabel independen yang lain. Untuk mendeteksi ada tidaknyamultikolinieritas dilakukan pengujian dengan metode VIF, yaitu dengan membandingkan nilai $\left(\mathrm{r}^{2}\right), \mathrm{X}_{\mathrm{i}}, \ldots . ., \mathrm{X}_{\mathrm{n}}$ dengan nilai $R^{2}$. Menurut L.R. Klein, masalah multikolinieritas baru menjadi masalah apabila derajatnya lebih tinggi dibanding dengan korelasi di antara seluruh variabel secara serentak. Apabila $\mathrm{r}^{2}<\mathrm{R}^{2}$ berarti tidak ada gejala multikolinieritas, tetapi jika $\mathrm{r}^{2}>\mathrm{R}^{2}$ maka model tersebut mengandung masalah multikolinieritas (Gujarati, 1999).

\section{c. Uji Heteroskedastisitas}

Tidak terpenuhinya asumsi terdapat varians yang sama dari setiap kesalahan penganggu $\left(\mathrm{e}_{\mathrm{i}}\right)$ akan menimbulkan gejala heterokedastisitas. Uji ini dilaksanakan untuk mengetahui apakah model penyimpang dari asumsi klasik yaitu homoskedastisitas, artinya varian tiap unsur disturbance (Vi) adalah suatu angka konstan yang sama dengan ${ }^{2}$. Berikut inilah yang disebut homokedastisitas atau varian yang sama (Gujarati, 1999).

\section{HASIL DAN PEMBAHASAN}

\section{Analisis Tingkat Keuntungan}

Hasil analisis data menunjukkan bahwa rata-rata penerimaan total per masa usaha penggemukan ternak sapi potong yang diperoleh tiap peternak sebesar Rp. 89.360.625.- (Tabel 21). Sedangkan biaya total rata-rata yang dikeluarkan peternak responden dalam satu masa penggemukan sapi adalah sebesar Rp. 85.264.600.-

Adapun rata-rata biaya yang dikeluarkan oleh peternak sampel yaitu biaya pakan konsentrat sebesar Rp. 7.388.727.- tiap peternak, biaya pakan hijauan sebesar Rp. 870.842.- tiap peternak biaya obat-obatan Rp. 217.842.- tiap peternak, biaya upah tenaga kerja Rp. 4.587.450.- tiap peternak, biaya sapi bakalan 71.488.500.- tiap peternak, biaya penyusutan peralatan Rp.41.987.- tiap peternak, biaya penyusutan kandang Rp. 414.184.- tiap peternak , biaya PBB Rp. 6.641.- tiap peternak, biaya listrik dan air Rp. 103.700.- tiap peternak dan biaya Transport Rp. 144.970.- tiap peternak.

Tingkat keuntungan yang diperoleh peternak dari hasil usaha peternakan sapi potong memberikan gambaran terhadap kondisi produksi peternakan sapi potong, dimana semakin tinggi tingkat keuntungan peternak dari hasil usaha peternakan sapi potong akan memberikan gambaran bahwa usaha peternakannya berhasil dan ini akan berdampak pada kesejahteraan peternak karena usaha peternakan akan memberikan kontribusi pada kesejahteraan peternak, begitu juga sebaliknya.

Pada umumnya sapi potong di Kabupaten Wonogiri dipelihara dengan cara tradisional, dimana jumlah pemilikan ternak dalam skala 
kecil, dengan modal, keterampilan dan teknologi yang masih terbatas. Peternakan yang dikelola secara tradisional masih mempunyai banyak kelemahan, diantaranya adalah pemanfaatan sumber daya produksi belum maksimal.

Analisis tingkat keuntungan usaha dihitung dengan memasukkan biaya total. Hasil analisis data menunjukkan bahwa usaha peternakan sapi potong di Kabupaten Wonogiri adalah secara finansial menguntungkan. Kondisi ini terlihat dari besarnya nilai penerimaan total yang melebihi biaya totalnya (TR $>\mathrm{TC}$ ).

Bahwa biaya total rata-rata sebesar Rp.85.119.873.- merupakan penjumlahan dari seluruh biaya rata-rata yang dikeluarkan dalam mendukung usaha penggemukan sapi. Penerimaan total (TR) dari usaha penggemukan sapi ini rata-rata sebesar Rp.89.360.625.- per satu masa penggemukan sapi potong, sehingga tingkat keuntungan () yang didapat tiap peternak dalam satu kali masa penggemukan sapi sebesar Rp.4.240.752.-

Tabel 2. Struktur Penerimaan Total, Biaya Total dan Tingkat Keuntungan Usaha Peternakan Sapi Potong Per Satu Kali Masa Penggemukan di Kabupaten Wonogiri

\begin{tabular}{lll}
\hline No $\quad$ Uraian & Frekuensi \\
\hline 1. Penerimaan Total (TR) & Rp. & $89.360 .625 .-$ \\
Biaya Total (TC)
\end{tabular}
Biaya Total (TC)

2. Biaya pakan konsentrat Rp. 85.119.873.Biaya pakan hijauan Rp. 7.388.727.Biaya obat Rp. 870.842.Biaya upah tenaga kerja Rp. 217.842.Biaya sapi bakalan

Biaya penyusutan kandang

Biaya penyusutan peralatan Biaya PBB

Biaya listrik dan air $\quad$ Rp. 41.987.Biaya transportasi Rp. 6.641.-

Rp. 103.700.Rp. 144.970.-

Tingkat Keuntungan
(=TR-TC)

Keterangan: Nilai TR > TC, dengan tingkat keuntungan usaha peternak yang menguntungkan $(>0)$, dan nilai $\mathrm{R} / \mathrm{C}=1,16$

Berdasarkan perhitungan tersebut maka dapat disimpulkan bahwa karena tingkat keuntungan peternak di atas Rp. 0,- ( > 0) dan nilai Return Cost Ratio (R/C) sebesar 1,16. Menurut Soekartawi (2003) bahwa suatu usaha dikatakan menguntungkan jika tingkat keuntungan () $>0$ dan nilai $\mathrm{R} / \mathrm{C}$ ratio di atas 1 . Maka dapat dikatakan bahwa usaha peternakan sapi potong rakyat di Kabupaten Wonogiri sangat menguntungkan secara finansial.

\section{Analaisis Fungsi Keuntungan}

Analisis regresi yang digunakan untuk menganalisis fungsi keuntungan adalah model analisis fungsi produksi Cobb-Douglas dengan spesifikasi fungsi keuntungan UOP-CDPF (Unit Output Price Cobb-Douglass Profit Function).

Dengan menggunakan software Eviews 9.0, maka diperoleh persamaan umum sebagai berikut :

\section{$\mathrm{LY}=25.387115711-1.50098057323 * \mathrm{LX} 1-$ $0.257347122778 *$ LX2 - $0.349614494485 *$ LX3 - $2.12821004307 *$ LX4 $+2.89402044135 *$ LX5 - $0.137550673377 *$ LX6}

Tabel 3. Hasil Analisis Regresi Pengaruh Beberapa Faktor terhadap Pendapatan Petani Ternak Sapi Potong di Kabupaten Wonogiri

\begin{tabular}{lllll}
\hline No & Variabel & $\begin{array}{l}\text { Koefisien } \\
\text { Regresi }\end{array}$ & t-hitung & $\begin{array}{l}\text { Probabilitas } \\
\text { Signifikansi }\end{array}$ \\
\hline 1. & LX1 & -1.500981 & -4.841712 & $0.0000^{* * *}$ \\
2. & LX2 & -0.257347 & -1.502613 & $0.1363^{\text {ns }}$ \\
3. & LX3 & -0.349614 & -1.542239 & $0.1264^{\text {ns }}$ \\
4. & LX4 & -2.128210 & -4.336637 & $0.0000^{* * *}$ \\
5. & LX5 & 2.894020 & 20.52081 & $0.0000^{* * *}$ \\
6. & LX6 & -0.137551 & -1.391189 & $0.1675^{\text {ns }}$ \\
& Adjusted & 0.831994 & & \\
& R-Square & & & \\
& F- & 82.71083 & & \\
& Statistik & & & \\
& F-Sig & 0.000000 & & \\
\hline
\end{tabular}

Sumber: Analisis Data Primer

Keterangan:

**) berpengaruh nyata pada tingkat kepercayaan $95 \%$

$\left.{ }^{* * *}\right)$ berpengaruh nyata pada tingkat kepercayaan $99 \%$

ns) tidak berpengaruh nyata pada tingkat kepercayaan $95 \%$ dan $99 \%$

\section{Pengaruh Variabel Biaya Pakan Konsentrat terhadap Tingkat Keuntungan Variabel biaya pakan konsentrat} berpengaruh nyata $(\mathrm{P}<0.05)$ terhadap variabel keuntungan peternak. Hal ini berarti menerima hipotesis kedua, artinya variabel independen biaya pakan konsentrat berpengaruh secara nyata terhadap variabel keuntungan yang diterima peternak penggemukan sapi potong.

Hal ini di sebabkan pemberian konsentrat pada sapi penggemukan sangat menentukan dalam pertambahan bobot badan dan efisiensi penggunaan pakan,sehingga efisiensi penggunaan konsentrat yang di iringi peningkatan berat badan 
sapi yang optimal akan dapat meningkatkan keuntungan , karena penggunaan konsentrat dalam ransum akan dapat meningkatkan nilai gizi ransum, yang juga akan membantu aktivitas mikroba menjadi optimal.

\section{Pengaruh Variabel Biaya Pakan Hijauan terhadap Tingkat Keuntungan}

Variabel biaya pakan hijauan tidak berpengaruh nyata $(\mathrm{P}>0.05)$ terhadap variabel keuntungan peternak. Hal ini berarti menolak hipotesis kedua, artinya variabel independen biaya pakan hijauan tidak berpengaruh secara nyata terhadap variabel keuntungan yang diterima peternak penggemukan sapi potong.

Hal ini terjadi karena pakan hijauan yang diberikan pada ternak sapi potong kuantitas dan kualitasnya rendah terutama pada saat musim kemarau, seperti rumput lapang dan limbah pertanian seperti limbah jerami padi, jerami jagung, jerami kedelai dan jerami kacang, tanpa ada sentuhan proses teknologi seperti fermentasi pakan. Hal ini disebabkan karena lahan kering Kabupaten Wonogiri merupakan daerah yang rawan kekeringan dengan tingkat kesuburan tanah yang rendah

\section{Pengaruh Variabel Biaya Obat Terhadap Tingkat Keuntungan.}

Variabel biaya obat tidak berpengaruh nyata $(\mathrm{P}>0.05)$ terhadap variabel keuntungan peternak. Hal ini berarti menolak hipotesis kedua, artinya variabel independen biaya obat tidak berpengaruh secara nyata terhadap variabel keuntungan yang diterima peternakpenggemukan sapi potong.

Hal ini terjadi karena tindakan pencegahan, penanggulangan dan pengobatan penyakit ternak sapi potong tidak dilakukan dengansecara baik oleh peternak, apalagi daerah lahan kering Kabupaten Wonogiri mempunyai suhu udara dan kelembaban udara yang tinggi sehingga memungkinkan semakin berkembangnya secara baik beberapa penyakit ternak tropis seperti penyakit scabies dan fasciola hepatica (cacing hati). Menurut Mubyarto (1999) bahwa perkembangan jenis ternak di Indonesia, juga dipengaruhi oleh curah hujan dan kesuburan tanah, serta dua faktor tambahan yakni kelembaban dan suhu udara.

\section{Pengaruh Variabel Biaya Upah Tenaga Kerja Terhadap Tingkat Keuntungan}

Variabel biaya upah tenaga kerja berpengaruh secara nyata $(\mathrm{P}<0.05)$ terhadap variabel keuntungan yang diterima peternak penggemukan sapi potong. Hal ini berarti menerima hipotesis kedua, artinya variabel independen biaya upah tenaga kerja berpengaruh secara nyata terhadap variabel keuntungan yang diterima peternak penggemukan sapi potong.

Hal ini terkait dengan perbedaan curahan jam kerja diantara peternak lebih di sebabkan oleh perbedaan waktu yang diperlukan untuk mencari hijauan dimana bagi peternak yang menempuh jarak yang lebih jauh akan menghabiskan waktu lebih lama sedangkan dalam pengelolaan ternak relatif sama seperti kebersihan kandang dan waktu pemberian pakan .

\section{Pengaruh Variabel Biaya Bakalan Sapi Terhadap Tingkat Keuntungan

Variabel biaya sapi bakalan
berpengaruh secara nyata $(\mathrm{P}<0.05)$ terhadap variabel keuntungan peternak. Hal ini berarti menerima hipotesis kedua, artinya variabel independen biaya bakalan berpengaruh secara nyata terhadap variabel keuntungan yang diterima peternak penggemukan sapi potong.

Hal ini disebabkan karena penjualan ternak sapi potong hasil penggemukan merupakan sumber penerimaan terbesar dari usaha penggemukan sapi potong. Jadi apabila semakin banyak jumlah ternak yang dimiliki, maka tingkat keuntungan pun akan ikut meningkat. Hal ini sesuai dengan penelitian Sudiyono et al. (2004) bahwa semakin banyak jumlah ternak sapi potong yang dipelihara maka semakin tinggi keuntungan peternak yang didapat.

\section{Pengaruh Variabel Biaya Penyusutan Kandang Sapi Terhadap Tingkat Keuntungan}

Variabel biaya penyusutan kandang tidak berpengaruh nyata $(\mathrm{P}>0.05)$ terhadap variabel keuntungan peternak. Hal ini berarti menolak hipotesis kedua, artinya variabel independen biaya penyusutan kandang tidak berpengaruh secara nyata terhadap variabel keuntungan yang diterima peternakpenggemukan sapi potong.

Biaya penyusutan kandang semakin lama waktu pemelihraan maka semakin besar biaya penyusutan kandang yang ditanggung. Biaya penyusutan kandang berbeda-beda pada skala usaha yang berbeda karena pada usaha tersebut, kandang yang digunakan sesuai dengan jumlah sapi yang diusahakan, berbeda dengan pendapat Rasyaf (2002), bahwa biaya tetap dalam usaha peternakan adalah biaya tetap yang terlibat dalam proses produksi dan tidak berubah meskipun ada perubahan jumlah hasil produksi yang dihasilkan. Teori ini berlaku jika semua peternak 
memiliki kandang yang sama dan skala usaha yang berbeda, akan tetapi kondisi lapangan dalam penelitian ini, peternak memiliki kandang berdasarkan skala sapi yang akan mereka pelihara jika peternak memelihara sapi dalam jumlah banyak maka kandang yang dibuat juga akan besar, sebaliknya jika jumlah ternak yang akan dipelihara sedikit maka luas kandangnya pun kecil.

\section{S1MPULAN}

Penerimaan total (TR) dari usaha peternakan sapi potong rakyat ini rata-rata sebesar Rp. 39.898.474.00 tiap peternak per satu masa penggemukan ternak sapi potong, sedangkan biaya totalnya (TC) rata-rata Rp.34.270.431,75 tiap peternak per satu masa penggemukan ternak sapi potong. Sehingga besarnya tingkat keuntungan (n) yang diperoleh tiap peternak dalam satu kali masa penggemukan ternak sapi potong sebesar Rp.5.628.042,25 dan nilai R/C Ratio 1.16 menunjukkan bahwa usaha peternakan sapi potong di Kabupaten Wonogiri menguntungkan secara finansial (nilai keuntungan it $>0$ dan nilai return cost ratio $\mathrm{R} / \mathrm{C}>1$ ).

Analisis persamaan regresi fungsi keuntungan peternak menunjukkan :

- Secara serentak biaya pakan konsentrat, biaya upah tenaga kerja dan biaya sapi bakalan berpengaruh nyata $((\mathrm{P}<0.05))$ terhadap tingkat keuntungan usaha peternakan sapi potongdi Kabupaten Wonogiri.

- Berdasarkan perhitungan nilai $\mathrm{R}^{2}$ didapatkan nilai adjusted $\mathrm{R}^{2}$ sebesar 0,832 . Ini berarti 83.2 persen variasi variabel biaya pakan konsentrat, biaya pakan hijauan, biaya obat, biaya upah tenaga kerja,biaya kandang dan biaya sapi bakalan dapat menerangkan dengan baik variabel tingkat keuntungan usaha peternak sapi potong. Sisanya 16.8 persen variabel tingkat pendapatan usaha peternak sapi potong dijelaskan oleh variasi variabel lain di luar model.

- Secara parsial variabel biaya pakan konsentrat, biaya upah tenaga kerja dan biaya sapi bakalan berpengaruh nyata $(\mathrm{P}<0,05)$ terhadap tingkat keuntungan usaha peternakan sapi potong rakyat. Sedangkan untuk variabel biaya pakan hijauan biaya obat tidak berpengaruh nyata $(\mathrm{P}>0,5)$ terhadap tingkat keuntungan usaha peternakan sapi potong rakyat.

\section{DAFTAR PUSTAKA}

Effendi. 1989. Metode Penelitian Survei, Jakarta: LP3ES

Gujarati,D. 1999. Basic Ekonometris. Jakarta:Penerbit PT.Erlangga.

Mandaka, S. dan M.P. Hutagaol. 2005. Analisis fungsi keuntungan, efisiensi ekonomi kemungkinan skema kredit bagi pengembangan skala usaha peternakan sapi perah rakyat di Kelurahan Kebon Pedes Kota Bogor. Jurnal Agro Ekonomi, Vol. 23 No.2, Oktober 2005. p:191-208.

Mubyarto . 1999. Pengantar Ekonomi Pertanian Edisi Ketiga. Jakarta: Penerbit LP3ES.

Rasyaf, M. 2002. Beternak Ayam Pedaging. Penebar Swadaya . Jakarta.

Roscoe, 1975, dikutip dari Uma Sekaran, 2006, Metode Penelitian Bisnis,. Salemba Empat, Jakarta.

Santoso,U.,Uka Kusnadi dan Dedi Sugandi .1996.Analisis Ekonomi Usaha Ternak Sapi Potong di Wilayah Jawa Barat.Laporan Hasil Penelitian.Lemlit Universitas Padjajaran Bandung.

Singarimbun. 1997. Metode Penelitian. Jakarta : Penerbit PT. Erlangga.

Soeharno, 2006. Teori Mikroekonomi. Andi Offset, Yogyakarta.

Soekartawi..2003. Teori Ekonomi Produksi dengan Pokok Bahasan Analisis Fungsi Cobb-Douglas. Jakarta: Penerbit PT.Raja Grafindo Persada.

Sudiyono, A. 2004.Pemasaran Pertanian. Universitas Muhamadiyah Malang.

Supranto. 2000.Statistik Teori dan Aplikasi. Jakarta : Erlangga. 